\title{
Impact of Insulin - Induced Hypoglycemia on some Plasma Markers of Skeletal Muscles and Heart Damage in Adult Male Rats: Relation to Oxidative Stress and Plasma Epinephrine
}

\author{
Manal M. Kamal and Asmaa F. Hassan \\ Department of Medical Physiology, Faculty of Medicine, \\ Assiut University, Assiut, Egypt
}

\begin{abstract}
SUMMARY
Objective: Hypoglycemic damage to the central nervous system is well known complication of insulin therapy. Little is known about the effect of insulin induced hypoglycemia on peripheral tissues as skeletal muscles and heart. In the present study the effect of acute and recurrent insulin- induced hypoglycemia on plasma creatine kinase (CK) and Lactate dehydrogenase (LDH); markers of skeletal muscles and heart damage was studied. Oxidative stress in those tissues and plasma epinephrine levels after hypoglycemia were also evaluated to elucidate the mechanism of hypoglycemic effect on those tissues. Methods: The study consisted of 50 adult male rats divided into three groups: (1) Control group. (2) Acute insulininduced hypoglycemia group (AHG): injected with human insulin (humulin) intraperitoneal (ip) in a dose of $10 \mathrm{U} / \mathrm{kg}$, food was then withheld for 6 hours. (3) Recurrent insulin-induced hypoglycemia group (RHG): received recurrent ip injection with $10 \mathrm{U} / \mathrm{kg}$ humulin once per day for three consecutive days, food is given after 2 hours and in the fourth day they received the same dose of insulin, then food was withheld for 6 hours. Blood glucose was measured before and 30, 60, 90 and 120 min after the injection. Plasma levels of CK, LDH were estimated before and 6 hours after the injection. Epinephrine levels were measured before and 90 min after the injection. Animals were sacrificed by decapitation $6 \mathrm{~h}$ after the injection for measurement of malondialdehyde (MDA) and total antioxidant capacity (T-AOC) in skeletal muscle and heart tissue homogenate. Results: it was found that acute and recurrent insulin induced hypoglycemia caused elevated levels of plasma $C K, L D H$, increase lipid peroxidations (MDA) together with decrease in T-AOC in skeletal muscle and heart tissue homogenate. The plasma epinephrine levels in response to hypoglycemia were significantly more in AHG group and RHG group at day 1 than control. It was also demonstrated that recurrent insulin induced hypoglycemia resulted in more increase in the levels of plasma CK, LDH and MDA with more decrease in T-AOC and blood glucose levels compared to acute insulin hypoglycemia rats. There was also revealed lower epinephrine levels in response to recurrent hypoglycemia at day 4 compared to control.

Conclusions: our findings indicate that acute and recurrent insulin induced hypoglycemia caused skeletal muscle and heart damage. This damage may be attributed to increased oxidative stress revealed in those tissues. This damaging effect
\end{abstract}


is more following recurrent hypoglycemia which may be related to the lower epinephrine levels in response to recurrent hypoglycemia detected in this group. That resulted in more decrease in blood glucose and therefore more damaging effects to those tissues.

\section{INTRODUCTION}

Intensive insulin therapy has led to significant reduction of long-term complications of diabetes ${ }^{(\mathbf{1})}$. However, hypoglycemia is the most frequent acute complication of this therapy ${ }^{(2)}$. Marked hypoglycemia represents a life-threatening medical emergency causing symptoms ranging from autonomic responses to seizures and coma. It is recognized to be an unfortunate "fact of life" for people who require insulin to maintain glycemic control, thereby, making a major limitation to intensive insulin therapy in those patients ${ }^{(3)}$. During hypoglycemia release of counter regulatory hormones especially epinephrine increased to maintain blood glucose homeostasis. This serves to correct and prevent hypoglycemia and restore euglycemia ${ }^{(4,5)}$. Most of the previous studies focused on the effect of acute hypoglycemic damage to the central nervous system $^{(6,7,8)}$. The central nervous system is extremely sensitive to hypoglycemic damage, because of the properties of the hematoencephalic barrier and the lack of other substrates in the $\mathrm{CNS}^{(\mathbf{9})}$.

Less attention has been paid to the effect of the acute hypoglycemic damage on peripheral tissues as skeletal muscles and heart. The decrease in substrate supply for energy perhaps affects those tissues as well. Furthermore, since recurrent exposure to hypoglycemia is common in patients on insulin therapy, it is less clear how recurrent hypoglycemia, as an important example of repeated physiological stressor impact at those tissues.

The presence of oxidative stress during hypoglycemia has been also suggested. Increased fatty acid metabolism in hypoglycemia lead to acidosis, which enhances free radical aggressivity ${ }^{(\mathbf{8}, 10)}$. Hypoglycemia and oxidative stress are mostly studied as two independent stressors. Therefore, the investigation of oxidative stress during hypoglycemia is important for both understanding the mechanism of hypoglycemic organ damage and for the possible prevention of this event.

The current study was undertaken to assess the consequences of the acute and recurrent insulin-induced hypoglycemia on plasma levels of creatine kinase and lactate dehydrogenase, the markers of skeletal muscles and heart damage. In addition, to evaluate oxidative stress on those tissues and plasma epinephrine levels in response to hypoglycemia to elucidate the mechanism of hypoglycemic effect on those tissues.

\section{MATERIALS \& METHODS}

\section{Animals}

The current study included a total number of 50 adult male SpragueDawley rats (age 3-5 months, weight 
220-310 grams). Animals were housed and cared for in the animal house of Faculty of Medicine Assiut University under constant healthy environment, maintained on a photobic period and fed a standard chow diet supplied from the animal house. Experimental protocols were in accordance with Animal Care and Use guidelines. All experiments were initiated at 8:00 am to minimize circadian variations. Rats were randomly divided into:

1- Control group: included 10 rats received intraperitoneal (ip) injection with normal saline.

2- Acute insulin-induced hypoglycemia group (AHG group): 20 non fasted rats. The basal levels of blood glucose were determined. Rats were then injected ip with regular soluble human insulin (Humulin-R 100 IU/ml from Lilly, Egypt - Eli USA) in a dose of $10 \mathrm{U} / \mathrm{kg}$. The dose of insulin and method of injection were chosen on the basis of data present in previous literatures $^{(11,12)}$. Following insulin injection food was withheld for 6 hours. The animals had free access to water during that time. Blood glucose was measured at 30, 60, 90 and $120 \mathrm{~min}$ after insulin injection. Animals were then sacrificed by decapitation 6 $\mathrm{h}$ after insulin injection.

3- Recurrent insulin-induced hypoglycemia group (RHG group): recurrent hypoglycemia was induced by recurrent ip injection with $10 \mathrm{U} / \mathrm{kg}$ Humulin once per day for three consecutive days in 20 non fasted rats in the same fashion as for the
AHG group. After 2 hours of the injection the rats were given free access to food to reverse hypoglycemia. This method was according to Herzog et al. ${ }^{(\mathbf{1 2})}$ and Fan et al. ${ }^{(13)}$. In the fourth day rats were injected with the same dose of insulin, food was withheld for 6 hours after that animals were sacrificed by decapitation. Blood glucose was recorded before and at 30,60, 90 and $120 \mathrm{~min}$ after insulin injection in the first and fourth day.

Biochemical assay:

Blood glucose: was determined in all groups using a glucometer and glucose test strips (Accutrend alpha Germany).

Plasma levels of Creatine kinase (CK) and Lactate dehydrogenase (LDH): determined by kinetic methods (Diagnostic Systems $\mathrm{GmbH}$, Germany) before and 6 hours after the injection of either insulin or saline in AHG group, RHG group in the fourth day and in control group.

Epinephrine assay: epinephrine was measured before and $90 \mathrm{~min}$ after the injection (11) in all groups. It was measured in AHG group and RHG group in the first day to detect the epinephrine level in response to acute hypoglycemia. It was also measured in RHG group at the fourth day to reveal the epinephrine level in response to recurrent hypoglycemia. Epinephrine concentrations were analyzed by ELISA kit (DRG international USA- EIA-4309).

Blood samples were collected, centrifuged and the plasma were separated, stored at $-20^{\circ} \mathrm{C}$ until determination of $\mathrm{CK}, \mathrm{LDH}$ and epinephrine levels. 
Malondialdehyde (MDA) and total antioxidant capacity (T-AOC): tissue samples of the quadriceps and whole heart were rapidly excised after decapitation, rinsed with physiological saline containing 0.16 $\mathrm{mg} / \mathrm{ml}$ heparin to remove any blood. Samples were minced using a hardmill, homogenized in potassium phosphate buffer ( $\mathrm{pH}$ 7.4). Homogenates were centrifuged for 20 min and the resulting supernatants were stored at $-20^{\circ} \mathrm{C}$. MDA the product of lipid peoxidation was quantitated by colorimetric method (Biodiagnostics- Egypt) employing the thiobarbituric acid reactive substance assay ${ }^{(\mathbf{1 4 , 1 5})}$. T-AOC was measured by chemical colorimetric method (Biodiagnostics- Egypt) according to Koracevic et al. ${ }^{(\mathbf{1 6})}$. Data were normalized to the amount of protein measured by the Lowry method $^{(17)}$, using the bovine serum albumen as a slandered.

\section{Statistical analysis:}

Data were analyzed with graph pad prism data analysis program. All data were expressed as means \pm SEM for all parameters. Differences in blood glucose levels measured at different time points were determined by using repeated measures ANOVA with Tukey post test. For each group paired two tailed Student's t test used to compare various levels tested before and after injection. Comparison between groups was made by unpaired two tailed Student's t test. Values were accepted as being statistically significant if $\mathrm{p}$ value was less than $0.05^{(\mathbf{1 8})}$.

\section{RESULTS}

1- Blood glucose levels before and after insulin injection: Figure 1

There were no differences among all groups in the baseline levels of blood glucose. After insulin injection the blood glucose levels dropped to statistically significant lower levels in AHG group, RHG group at day 1 and 4 when compared to control values at 30, 60, 90 and $120 \mathrm{~min}$ time points $(\mathrm{p}<0,001$ for all).In RHG rats at day 4 the blood glucose levels were significantly lower than those recorded on the same group at day 1 after insulin injection at the $30,60,90$ and 120 min time points $(\mathrm{P}<0.01)$.

2. Plasma epinephrine levels: Table 1

During the baseline period, the mean values of epinephrine levels did not differ significantly between all studied groups. After $90 \mathrm{~min}$ of insulin or saline injection the levels measured were significantly higher than initial values in AHG group, RHG group at day 1 and in control group ( $\mathrm{P}<0.001$ for all). Those increased levels were significantly more pronounced in AHG and RHG group (day1) when compared to control levels ( $\mathrm{P}<0.001$ for both). In RHG group at day 4, although the mean value of epinephrine levels measured 90 min after insulin injection was significantly higher than initial mean value $(\mathrm{P}<0.001)$; this increased value was significantly less than that detected in control after 90 min of saline injection $(\mathrm{P}<0.01)$.

3. Plasma CK and LDH activity: Table 2

The baseline mean values of plasma CK and $\mathrm{LDH}$ levels did not 
differ significantly among all groups. Insulin-induced hypoglycemia remarkably increased the plasma $\mathrm{CK}$ levels measured 6 hours after insulin injection in $\mathrm{AHG}$ group and $\mathrm{RHG}$ group in day 4 when compared to baseline values $(\mathrm{P}<0.001$ for both) with percent increase than baseline values of $101.7 \%$ and $151 \%$ respectively. A significant increase of mean values of plasma LDH levels was also observed after 6 hours of insulin injection in $\mathrm{AHG}$ group and RHG group (day 4) when compared to baseline values $(\mathrm{P}<0.001$ for both). With percent increase than baseline values of $95.3 \%$ and $127.8 \%$ respectively.

The levels of both enzymes detected in RHG (day 4) $6 \mathrm{~h}$ after insulin injection were notably greater compared to those of AHG group $(\mathrm{P}<$ 0.01 for both $\mathrm{CK}$ and $\mathrm{LDH})$. The percent increase of levels of both enzymes than baseline values were also more in RHG (day 4) than those of AHG (151\% versus $101.7 \%$ for CK and $127.8 \%$ versus $95.3 \%$ for $\mathrm{LDH}$ ). In control group, the mean values of plasma levels of both $\mathrm{CK}$ and $\mathrm{LDH}$ evaluated $6 \mathrm{~h}$ after saline injection show slight but insignificant increase than initial values. With percent increase than baseline values of only $10.9 \%$ for $\mathrm{CK}$ and $16.3 \%$ for $\mathrm{LDH}$.

\section{MDA and T-AOC levels in the tissues homogenate of skeletal muscle and heart: Figures 2 and 3.}

Our results showed that increased lipid peroxidation in skeletal muscle and heart tissue homogenate was found in AHG and RHG group (day4) after $6 \mathrm{~h}$ of insulin induced hypoglycemia. This was expressed in both groups by the higher levels of MDA detected in those tissues than control levels (Fig 2) $(\mathrm{p}<0.001$ for all). Whereas, the mean values of the levels of T-AOC (Fig 3) estimated in skeletal muscle and heart tissues of both groups were significantly less than control mean values $(\mathrm{p}<0.001$ for all).

These changes were more evident in RHG group (day 4) compared with AHG group: MDA levels were significantly higher in RHG group (day 4) than levels detected in AHG group in skeletal muscle (4.475 \pm 0.31 vs. $3.3 \pm 0.28, \mathrm{p}<0.01)$ as well as in heart $(5.15 \pm 0.32$ vs. $3.48 \pm 0.34, \mathrm{p}<0.001)$. On the other hand, T-AOC levels were significantly lower in skeletal muscle (33.15 $\pm 1.33 \mathrm{vs} 41.10 \pm 2.49, \mathrm{p}<0.01)$ and in heart $(30.50 \pm 1.65$ vs37.65 $\pm 2.39 \mathrm{p}<0.05)$. 


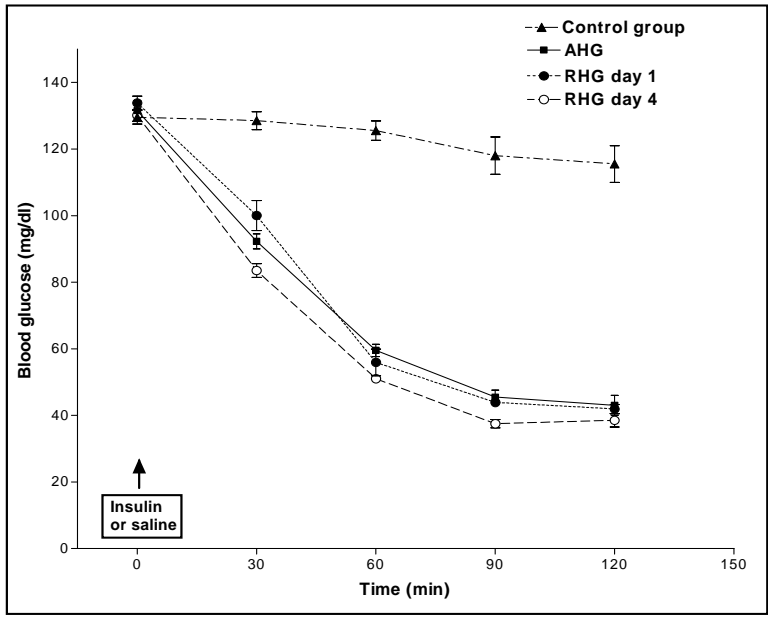

Figure (1): Blood glucose levels before and after insulin or saline injection in control group, acute hypoglycemia group (AHG), recurrent hypoglycemia group at day 1 (RHG dayl) and at day 4 (RHG day 4).

Table (1): The mean values $\pm \mathrm{SE}$ of plasma epinephrine leve $\mathrm{s}(\mathrm{pg} / \mathrm{ml})$ in control group, acute hypoglycemia group (AHG), recurrent hypoglycemia group at day 1 (RHG day1) and at day 4 (RHG day 4) at baseline and 90 min after saline or insulin injection.

\begin{tabular}{|l|c|c|}
\hline \multicolumn{1}{|c|}{ Groups } & Baseline values & 90 minute after the injection \\
\hline Control & $208.0 \pm 15.02$ & $1388 \pm 34.07^{\mathrm{a}}$ \\
AHG & $233.5 \pm 32.43$ & $2346 \pm 74.03^{\mathrm{a}} \mathrm{b}$ \\
RHG day 1 & $266.0 \pm 31.31$ & $2131 \pm 98.94^{\mathrm{a}}{ }^{\mathrm{b}}$ \\
RHG day 4 & $220.0 \pm 18.67$ & $1095 \pm 79.63^{\mathrm{a}}{ }^{\mathrm{c}}$ \\
\hline
\end{tabular}

${ }^{\mathrm{a}}=\mathrm{P}<0.001$ versus baseline values; ${ }^{\mathrm{b}}=\mathrm{P}<0.001$ versus control, ${ }^{\mathrm{c}}=\mathrm{P}<0.01$ versus control.

Table (2): The mean values $\pm \mathrm{SE}$ and the percent changes in the plasma CK and LDH in control group, acute hypoglycemia group (AHG) and recurrent hypoglycemia group at day 4 (RHG day4) at baseline and $6 \mathrm{~h}$ after saline or insulin injection.

\begin{tabular}{|c|l|c|c|c|}
\hline \multicolumn{1}{|c|}{ Enzymes } & \multicolumn{1}{|c|}{ Groups } & $\begin{array}{c}\text { Baseline } \\
\text { values }\end{array}$ & $\begin{array}{c}6 \text { h after the } \\
\text { injection }\end{array}$ & $\begin{array}{c}\text { Percent } \\
\text { Change }\end{array}$ \\
\hline CK (U/L) & Control & $218.5 \pm 7.07$ & $242.4 \pm 12.11^{\mathrm{NS}}$ & $10.9 \% \uparrow$ \\
& AHG & $203.5 \pm 6.93$ & $410.4 \pm 28.05$ a & $101.7 \% \uparrow$ \\
& RHG day 4 & $232.0 \pm 18.32$ & $582.4 \pm 39.36^{\text {a, b }}$ & $151 \% \uparrow$ \\
& Control & $226.4 \pm 7.56$ & $263.4 \pm 18.47^{\mathrm{NS}}$ & $16.3 \% \uparrow$ \\
& AHG & $221.9 \pm 5.79$ & $433.3 \pm 25.26^{\mathrm{a}}$ & $95.3 \% \uparrow$ \\
LDH (U/L) & RHG day 4 & $248.5 \pm 12.27$ & $566.2 \pm 36.33^{\mathrm{a}, \mathrm{b}}$ & $127.8 \% \uparrow$ \\
& \multicolumn{2}{|c}{} \\
\hline
\end{tabular}

NS $=$ non significant versus baseline value; - $^{\mathrm{a}}=\mathrm{P}<0.001$ versus baseline values; ${ }^{\mathrm{b}}=\mathrm{P}<0.01$ versus $\mathrm{AHG}$ group; $\uparrow=$ increase. 


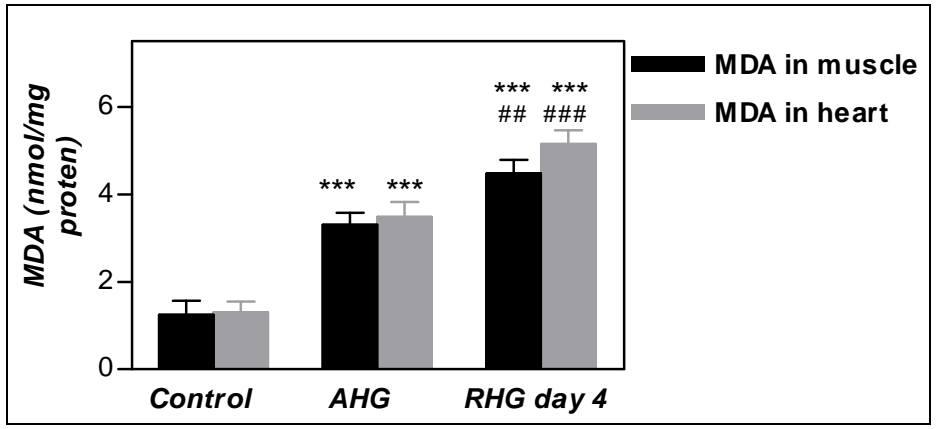

Figure (2): Muscle and heart malondialdehyde (MDA) levels in control group, acute hypoglycemia group (AHG) and recurrent hypoglycemia group at day 4 (RHG day 4). ***: $\mathrm{P}<0.001$ versus control; \#\# $\mathrm{P}<0.01$ versus $\mathrm{AHG}$ group; \#\#\# $<0.001$ versus $\mathrm{AHG}$ group.

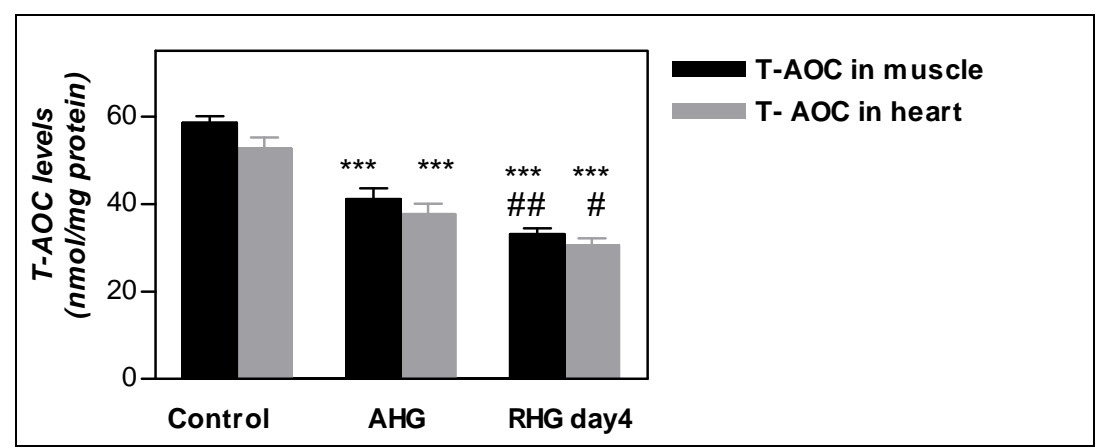

Figure (3): Muscle and heart total antioxidant capacity (T-AOC) levels in control group, acute hypoglycemia group (AHG) and recurrent hypoglycemia group at day 4 (RHG day 4).

***: $\mathrm{P}<0.001$ versus control; \#\# $\mathrm{P}<0.01$ versus AHG group; \# $\mathrm{P}<0.05$ versus AHG group.

\section{DISCUSSION}

In the present study insulin induced hypoglycemia resulted in a remarkable rise in plasma $\mathrm{CK}$ and $\mathrm{LDH}$ in AHG and RHG rats (day4) after 6 hours of insulin injection. CK and LDH are cytoplasmic enzymes, their plasma activity increased due to their leakage through membranes of damaged cells. CK is an enzyme which catalyses the reversible transfer of the phosphoryl group from phosphocreatine to ADP to regenerate ATP. Whereas, LDH is a key enzyme involved in the process of conversion of lactic acid to pyruvate ${ }^{(19)}$. Plasma activity of $\mathrm{CK}$ was reported to increase by the experimental occlusion reperfusion of coronary 
$\operatorname{artery}^{(20)}$ and also in sinovastation treated rabbits showing skeletal muscle damage ${ }^{(21)}$. CK is known to be a muscle-localized enzyme, and thus many investigators suggest that increase CK plasma levels is a basic diagnostic indicator used for early detection of pathological damage of the skeletal and or cardiac muscles $^{(22,23,24)}$.

Increased the plasma level of LDH is also considered a marker of skeletal and or cardiac muscle injury. This is because its highest activity found in skeletal muscles and heart ${ }^{(25,26)}$. Accordingly, the increased in plasma CK and LDH levels found in this study suggests that either acute or recurrent hypoglycemia cause pathological damage to the skeletal muscles and or heart. Other previous studies ${ }^{(23,27,28)}$ demonstrated a remarkable rise in plasma $\mathrm{CK}$ and LDH by insulin induced hypoglycemia. In addition to increase the plasma levels of alanine aminotransferase(ALT), aspartate aminotransferase (AST), which are all primarily due to damage in skeletal muscles and heart.

Further, we studied the alteration of MDA and T-AOC levels in skeletal muscle and heart tissues after insulin induced hypoglycemia. MDA is a marker of lipid peroxidation, while TAOC reflects the capacity for elimination of free radicals ${ }^{(29)}$. Significant increase of MDA and significant reduction of T-AOC levels in the skeletal muscle and heart tissues were found after $6 \mathrm{~h}$ of insulin injection in AHG and RHG (day 4) groups compared to control. These results indicate that either acute or recurrent insulin induced hypoglycemia is associated with oxidative stress.

These results are comparable to other previous studies found that oxidative stress could be triggered by hypoglycemia. In the study of Patockova et $\mathrm{al}^{(30)}$ it was observed that a significant increase of lipid peroxidation induced by insulin hypoglycemia in tissues of the brain and heart of mice, which provided the evidence of oxidative stress in those tissues. Additionally, in the study of Jiang et al. ${ }^{(28)}$ it was found that administration of antioxidant as reduced glutathione prevented the increased serum enzymes following experimental hypoglycemia. Hyperinsulinemia had also been supposed to cause oxidative stress ${ }^{(31)}$. However, the after wards study of Patočková et al. $^{(9)}$ showed that increase in lipid peroxidation is dependent on the severity of hypoglycemia but not on the insulin dosage.

Considerable evidence suggested that oxidative stress plays an important role in neuronal death associated with hypoglycemia ${ }^{(9,32)}$. This also had a role in other hypoglycemic tissues damage as liver, kidney $^{(33)}$ and the heart ${ }^{(30)}$. Oxidative damage to skeletal muscle and heart follow hypoglycemia is suggested in this study. This oxidative damage could be explained based on previous observation that during hypoglycemia, the skeletal muscles would be a target for glucose counter regulation in the periphery. First, by reduction of glucose uptake by muscles thus, makes more glucose available to the brain. Second, there is activation of glycogen phosphorylase and 
inhibition of glycogen synthase enzymes with mobilization of gluconeogenic substrates from glycogen stores in muscles to the liver ${ }^{(34,35)}$

Prolonged insulin-induced hypoglycemia decreases the substrate supply for energy metabolism in muscles. A change in oxidation reduction in muscles consequently will result due to depletion of intracellular adenosine triphosphate ${ }^{(27)}$. Hypoglycemia may also suppress energy metabolism and increase ineffective glucose metabolism in the heart. It was reported that insulin induced hypoglycemia caused heart failure, angina pectoris and myocardial infarction. These effects were attributed to insufficient energy production for the increased left ventricular load ${ }^{(7,36)}$. In support of this, it was found that other conditions of energy impairment or failure such as ischemia or glycolysis inhibition also involves oxidative damage ${ }^{(37,38)}$ .Increased acidity during prolonged hypoglycemia occurs as a result of increased fatty acid metabolism. This will additionally augment free radical destructive effects ${ }^{(\mathbf{8 , 1 0})}$.

In keeping with these data, the results of the current study demonstrate that either acute or recurrent insulin induced hypoglycemia caused energy impairment in skeletal muscle and heart. This produced oxidative stress to these tissues and resulted in oxidative damage to their cell membranes. Thus, providing a possible explanation of hypoglycemic damage affecting those tissues that was represented by increased plasma $\mathrm{CK}$ and $\mathrm{LDH}$.

The present study demonstrates that, the increase in plasma levels of $\mathrm{CK}$ and $\mathrm{LDH}$ and their percent increase than baseline values were more obvious in RHG group (day 4) compared to those of AHG group. There was also more rise of MDA with more reduction of T-AOC levels in the skeletal muscle and heart tissues compared to AHG group. Presumably, these results were mediated by the significant decline in blood glucose levels in RHG group in day 4 when compared to either AHG or RHG group at day 1. This lower glucose levels is expected to cause more energy impairment and thus increased oxidative stress leading to more muscle and heart tissue damage represented by elevated plasma CK and LDH levels. This is supported by the study of Jiang et al. ${ }^{(27)}$ finding that hypoglycemic organ damage including skeletal muscles and heart tends to increase in severity according to the severity of hypoglycemia.

The significant lower levels of blood glucose after insulin injection in RHG group (day 4) can be explained by the impaired epinephrine response reported in this group. Our results showed that after $90 \mathrm{~min}$ of the injection there were significant higher levels of epinephrine in AHG group, RHG group at day 1 than control levels. This increase is expected in response to hypoglycemia to counteract for the low blood glucose ${ }^{(39)}$. On the other hand, the levels detected in RHG group at day 4 were significantly less than control levels. This denotes that 3 days of insulin-induced hypoglycemia 
resulted in diminished epinephrine response to subsequent hypoglycemia. This finding agrees with other previous studies as those of Flanagan et al. ${ }^{(11)}$, Song and Routh ${ }^{(5)}$ and Herzog et al. ${ }^{(\mathbf{1 2})}$. It was clearly demonstrated that recurrent hypoglycemia impairs the sympathoadrenal and neuroendocrine counterregulatory responses to hypoglycemia that normally restore euglycemia. This represents acute adaptation to a repeated metabolic stressor and results from a decreased ability of some brain regions, the ventromedial hypothalamus in particular to sense hypoglycemia. That will increase brain glucose threshold for detection of hypoglycemia. Thus, brain glucose levels are allowed to fall to dangerous or even lethal levels before the counter regulatory responses are initiated $^{(5,40)}$.

It is less certain how recurrent insulin-induced hypoglycemia with impaired epinephrine secretion impact at the peripheral tissue. Epinephrine exert some of its insulin antagonistic effects in the periphery by decreasing peripheral glucose uptake, mobilize substrates and fuel for gluconeogenesis, inhibit glucose metabolism in muscle and adipose tissue $^{(\mathbf{4 1 )}}$. However, the critical role of epinephrine during hypoglycemia is in large part due to its potent lipolytic effect on skeletal muscle and adipose tissue. Although it is well known that adipose tissue is the principle source of lipid-derived fuel (NEFA and glycerol), it was found that there is significant intramuscular lipolysis as well $^{(42)}$, According to this scenario, recurrent insulin induced hypoglycemia amplifies the potential for hypoglycemic damage by inhibiting epinephrine -induced lipolysis. Defective stimulation of lipolysis in skeletal muscle and adipose tissue is associated with an inappropriate increase in muscle and heart glucose disposal. These pathophysiological changes may be important contributors to the development of hypoglycemic muscle and heart damage following recurrent hypoglycemia $^{(41)}$.

In summary, there is evidence from the results of the present study and the fore mentioned discussion that acute and recurrent insulin induced hypoglycemia caused skeletal muscle and heart damage. That was represented by a significant increase in plasma $\mathrm{CK}$ and $\mathrm{LDH}$ levels. This could be explained by increased oxidative stress detected in those tissues that resulted from glucoprivation. The damaging effect is more evident following recurrent hypoglycemia which may be attributed to the suppressed epinephrine response to recurrent hypoglycemia causing more decrease in blood glucose and thus more damage to these tissues.

\section{REFERENCES}

1. The Diabetes Control and Complications Trial Research Group (DCCTRG) (1997): Hypoglycemia in the Diabetes Control and Complications Trial. Diabetes; 46:271-286.

2. Cryer, P.E. (2004): Diverse causes of hypoglycemiaassociated autonomic failure in 
diabetes. N Engl J Med.; 350:2272-2279.

3. Cryer, P.E.; Davis, S.N.; Shamoon, H. (2003): Hypoglycemia in diabetes. Diabetes Care; 26: 1902-1912.

4. UK Prospective Diabetes Study Group (UKPDS) (1998): Intensive blood-glucose control with sulphonylureas or insulin compared with conventional treatment and risk of complications in patients with type 2 diabetes. Lancet; 352: 837-853.

5. Song, Z. and Routh, V.H. (2006): Recurrent hypoglycemia reduces the glucose sensitivity of glucose-inhibited neurons in the ventromedial hypothalamus nucleus. Am J Physiol Regul Integr Comp Physiol.; 291: R1283-R1287

6. Courten-Myers, J.M.; Guohua, Xi.; Hwang J.H.; Scott, D.R.; and Myers R. E. (2000): Hypoglycemic brain injury: potentiation from respiratory depression and injury aggravation from hyperglycemic treatment overshoots. Journal of Cerebral Blood Flow \& Metabolism; 20: 82-92.

7. Brian, M.F. (2004): Morbidity of hypoglycemia in type 1 diabetes. Diabetes Research and Clinical Practice; 65S: S47-S52.

8. Haces, M.L.; Montiel, T. and Massieu, L. (2010): selective vulnerability of brain regions to oxidative stress in non coma model of insulin induced hypoglycemia. Neuroscience; 165: 28-38.

9. Patockova, J.; Marhol, P.; Tumova, M; Kriak, M.; and Andel, M. (2003 b): Oxidative stress in the brain tissue of laboratory mice with acute post insulin hypoglycemia. Physiol. Res. 52: 131-135.

10. Suh, S.W.; Hamby, A.M.; Gum, E.T.; Shin, B.S. and Swanson, R.A. (2008): Sequential release of nitric oxide, zinc, and superoxide in hypoglycemic neuronal death. J Cereb Blood Flow Metab.; 28:1697-1706.

11. Flanagan, D.E.; Keshavarz, T.; Evans, M.L.; S.; and; Sherwin, R.S. (2003): Role of corticotrophin-releasing hormone in the impairment of counterregulatory responses to hypoglycemia. Diabetes; 52: 605 $-613$.

12. Herzog, R.I.; Sunkyung Yu, O.C.; Dziura, J.; and Robert, S. (2008): Effect of acute and recurrent hypoglycemia on changes in brain glycogen concentration. Endocrinology; 149(4): 1499-1504.

13. Fan, X.; Ding, Y.; Cheng, H.; Dorte, X.; Robert,S.; and Roy, J. (2008): Amplified hormonal counterregulatory responses to hypoglycemia in rats after systemic delivery of a SUR-1selective $\mathrm{K}^{+}$channel opener. Diabetes; 57 (12): 3327-3334.

14. Satoh, K. (1978): Serum lipid peroxide in cerebrovascular disorder determined by a new coloimetric method. clinica chimica acta; 90: 37- 43.

15. Ohkawah; Ohisihin; Yagik (1979): Assay for lipid peroxides in animal tissues by thiobarbituric acid reaction. Anal Biochem.; 95: 351-358. 
16. Koracevic, D.; Koracevic, G.; Djordjevic, V.; Andrejevic, S. (2001): Method for the measurement of antioxidant activity in human fluids. J Clin Pathol; 54(5):356-361.

17. Lowery, O.H.; Rosebrough, N.J.; Randoll, R.J. (1951): protein measurement with the folin phenol reagent. J. boil. Chem.; 193: 265- 275.

18. Knapp GR and Miller MC(1992): Tests of statistical significance :Regression and correlation .In Clinical Epidemiology and Biostatistics 1 st Eddition Williams and Wilkins ,Baltimore ,Maryland.P:255-274

19. Wallimam, T.; Wyss, M.; Bradiczka, D.; Nicolay, K.; Eppenberger, M. (1992): Intracellular compartmentation, structure and function of creatine kinase isoenzymes in tissues with high and fluctuating energy demands: the "phosphocreatine circuit" for cellular energy homeostasis. Bioch. J.; 28: 2140.

20. Ohmuro, S.; Tsukada, Y.; Taga, F. (1992): Protective effect of the new antiplatelet agent 2methy 1-3-(1,4,5,6-tetrahydronicotinoyl) pyrazolo (1,5-a) pyridine on myocardial damage due to coronary occlusion and reperfusion in rabbit. Drug Res.; 42:39-42.

21. Fukami, M.; Maeda, N.; Fukushige, J. (1993): Effects of HMG-CoA reductase inhibitors on skeletal muscles of rabbits. Res Exp Med.; 193:263-273.

22. Horder, M.; Jorgensen, P. J.; Hafkenscheid, J. $\quad$ C.; Carstensen, C. A and Vogt, W. (1991): Creatine kinase determination: a European evaluation of the creatine kinase determination in serum, plasma and whole blood with the Reflotron system. Eur J Clin Chem Clin Biochem.; 29: 691696.

23. Mitani, s.; Okumura, A.; Matsui, H.; Toki, Y. and Hashimoto, H. (2000): Insulin alters muscle creatine kinase activity. Heart vessel .15: 23-29.

24. Lihua, H.E.; Guozhen, L.; Xin, F.E.; and Sheng Wang (2008): Effect of energy compound on skeletal muscle strain injury and regeneration in rats. Industrial health; 46, 506-512.

25. Naraoka, H.; Ito, K.; Suzuki, M.; Naito, K.; Tojo, H. (2005): Evaluation of $\mathrm{H}_{-}$FABP as a marker of ongoing myocardial damage using HCG transgenic mice. Clin chim. Acta.; 36: 159166.

26. Okhuwa, T.; Saito, M. and miyamura (2007): Plasma LDH and CK activities after $400 \mathrm{~m}$ springing by well trained runners. European journal of applied physiology and occupational physiology. 52, 3: 296-299.

27. Jiang, Z.L.; Harada, T.; Yokokawa, M.; Kohzuki, M.; Sato, T.; (1998): Muscle damage induced by experimental hypoglycemias. Metabolism; 47: 1472-1476.

28. Jiang, Z.L.; Kohzuki, M.; Harada, t.; Sato, T. (2007): Glutathione suppresses increase of serum creatine kinase in experimental hypoglycemia. Diabetes Research and Clinical Practice; 77: 357-362.

29. He, B.; Zhao, S.; Zhang, W.; Li, L. and Han, P. (2010): Effect of 
sodium salicylate on oxidative stress and insulin resistance induced by free fatty acids Hepatobiliary Pancreat Dis.; 9: 115.

30. Patockova, J.; Kriak, M.; Marhol, P.; Tumova, M (2003 a): Cerebrolysin inhibits lipid peroxidation induced by insulin hypoglycemia in the brain and heart of mice. Physiol. Res.; 52: 455-446.

31. Paolisso, G. and Giugliand, D. (1996): Oxidative stress and insulin action: is there a relationship. Diabetologia; 39: 357-363.

32. Razavi, N.L.; Kitabchi, A.E.; Stenz, F.B and; Taheri, E. (2009): Proinflamatory cytokines in response to insulin induced hypoglycemia stess in healthy subjects. Metabolism; 58 (4):443448.

33. Bhardwaj, S.K.; Sharma, M. L.; Gulati, G.; Chhabara, A and Kaur, G. (1998): Effect of starvation and insulin induced hypoglycemia on oxidative stress scavenger system and electron transport chain complexes from rat brain, liver and kidney.mol chem. Neuropathol.; 34: 157168.

34. Davis, M. and Shamoon, H. (1991): Adaptive counterregulatory responses to hypoglycemia in nondiabetic humans. J. Clin. Endocrinol. Metab.; 73: 995-1001.

35. Shamoon, H.; Friedman, S.; Canton, C.; Zacharowicz, L and Rossetti, L. (1994): Increased epinephrine and skeletal muscle responses to hypoglycemia in non-insulin- dependent diabetes mellitus. J. Clin. Invest.; 93: 2562-2571.

36. Minna, L.; Koivikko; Pasi; Salmela, K.E.; Juhani Airaksinen, and Juha S. (2005): Effects of sustained insulininduced hypoglycemia on cardiovascular autonomic regulation in type 1 diabetes. Diabetes; 54:744-750.

37. Tomizawa, S.; Imai, H.; Tsukada, S.; Simizu, T.; Honda, F.; and Nakamura, M.; (2005): the detection and quantification of highly reactive oxygen species using the novel HPF fluresence probe in a rat model of focal cerebral ischemia. Neuroscience res.; 53: 304-313.

38. Adibhatla, M.R.; and Hacher, J.F. (2006): phospholipase A2, reactive oxygen species and lipid peroxidation in cerebral ischemia. Free radical boil med.; 4: 376387.

39. Bouman, S.D. (2009): Counterregulation to acute and recurrent hypoglycemia in rats. Dutch Diabetes Research; (1): 111-116.

40. Cryer, P. E. (2005): Mechanisms of hypoglycemia-associated autonomic failure and its component syndromes in diabetes. Diabetes; 54: 35923601.

41. Enoksson, S.; Sonia, K.; Caprio, S.W. and Sherwin, R. S. (2003): Defective activation of skeletal muscle and adipose tissue lipolysis in type 1 diabetes mellitus during hypoglycemia. The Journal of Clinical Endocrinology \& Metabolism; 88: (4) 1503-1511.

42. Fanelli, C.G.; De Feo, P.; Porcellati, F.; Brunetti, P.; and 
Bolli, G. B. (1992): Adrenergic mechanisms contribute to the late phase of hypoglycemic glucose counterregulation in humans by stimulating lipolysis. J Clin Invest.; 89: 2005-2013.

\section{تأثير نقص سكر الام المحدث بالأنسولين على بعض دلالات إعتلال العضلات الهيكلية والقلب بالبلازما في الجرذان الأكور البالغين : علاقته بالإجهاد التأكسدى وإبينيفرين البلازما. التورئ

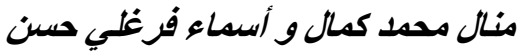

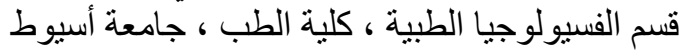

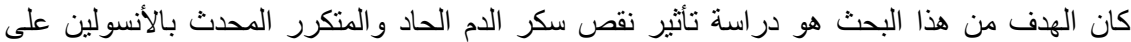

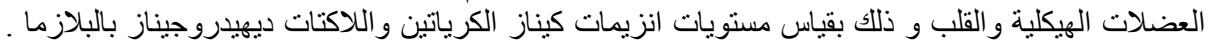

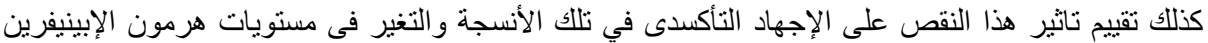
بالبلازما و دور هم فى تضرر العضلات العيلات الهيكلية و القلب.

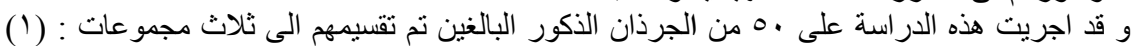

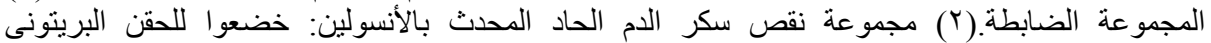

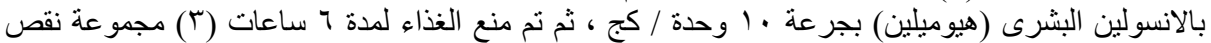

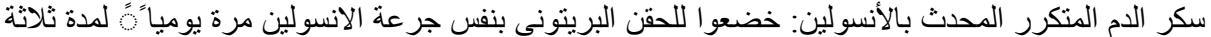

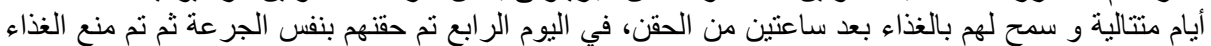

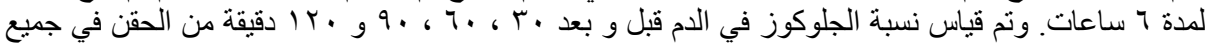

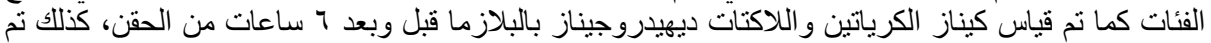

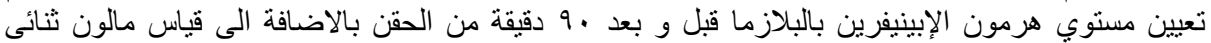

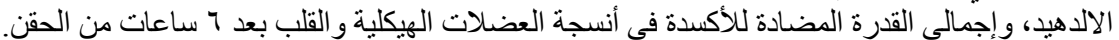

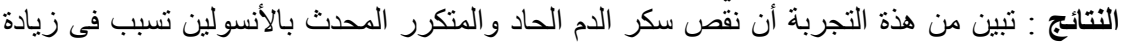

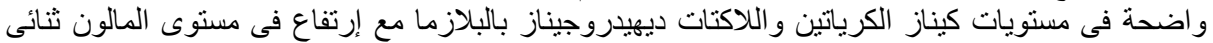

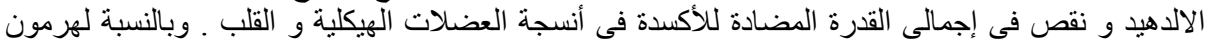

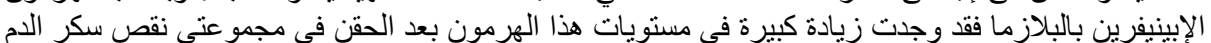

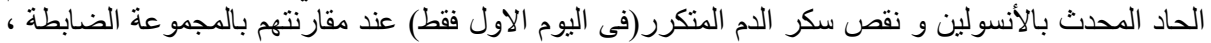

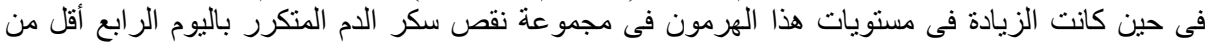
المجمو عة الضابطة النياد

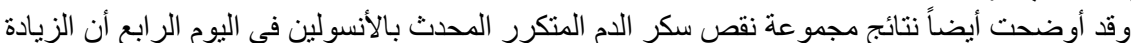

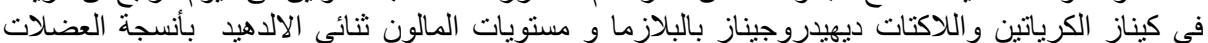

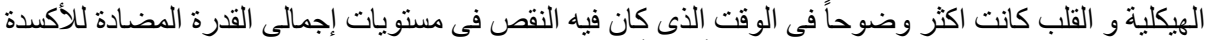

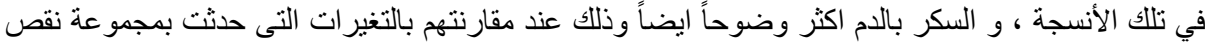

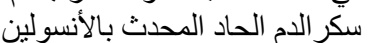

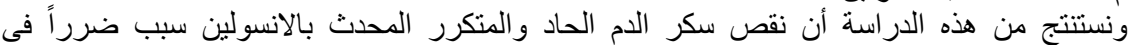

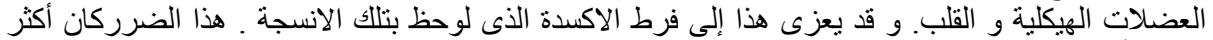

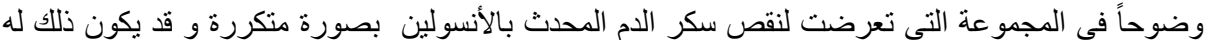

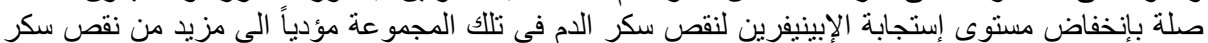
الدم و بالتالى المزيد من تضرر نلإلك الانسجة. 